\title{
HEATING OF THREE-PHASE SHIELDED SUPPLY AT SHORT CIRCUIT
}

\author{
Daniel MAYER, Bohuš ULRYCH, Petr KROPÍK \\ Department of Theory of Electrical Engineering, Faculty of Electrical Engineering, University of West Bohemia, Pilsen, \\ Czech Republic, e-mail: mayer, ulrych,pkropik@kte.zcu.cz
}

\begin{abstract}
Following the calculation of the mechanical forces acting on the shielded three-phase line published in [1] and [2], an algorithm describing numerical calculation of its temperature rise due to short-circuit currents is presented. Given are the equation for determining the electromagnetic sources of heating, heat transfer equation for propagation of heat in the line and another equation for a simplified calculation of the temperature rise of the line provided that the investigated temperature process is adiabatic. The methodology is illustrated with a typical example.
\end{abstract}

Keywords: shielded three-phase line, three-phase short circuit, heating of three-phase line

\section{FORMULATION OF PROBLEM}

Feeding lines of high-power electrical rotating machines, transformers, arc furnaces and many other devices are highly stressed mechanically and thermally, in particular at short circuit. Mechanical stresses on these conductors can significantly be reduced using wires shielded with steel jackets, see [1] and [2]. On the other hand, the presence of shielding complicates local thermal situation; it reduces the possibility of transfer of heat from the conductor and, moreover, further losses by eddy currents induced in the shielding jackets are generated, representing additional sources of heat. The paper describes a method for calculation of heating of such a shielded conductor. The paper supplements the above works, as it describes the method of calculation of temperature rise of feeding lines. The results allow carrying out such a design of the line that is safe with respect to the thermal damage of its insulation.

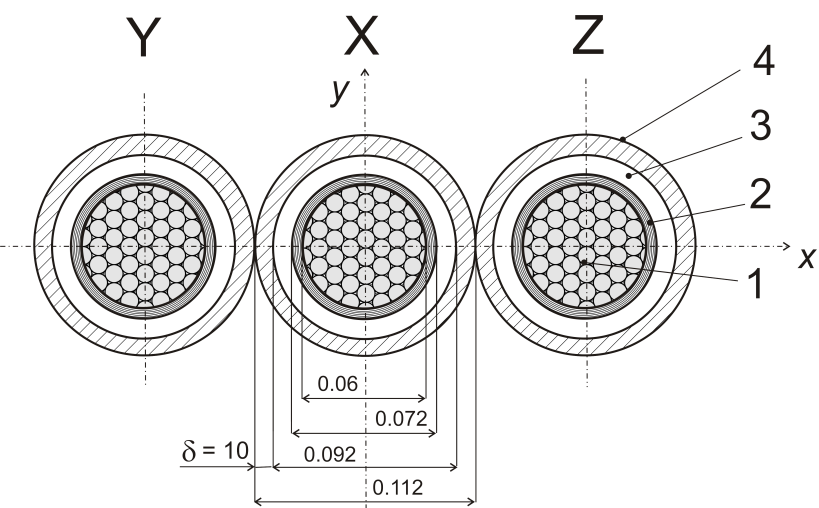

Fig. 1 Arrangement of the shielded conductors: 1-Copper core of the cable, 2-Insulation, 3-Setting blocks, 4-Shielding jackets

Consider a three-phase line represented by straight conductors X, Y, Z. The conductors can be either massive or created by electrically conductive ropes that are insulated and placed in the shielding steel jackets, see Fig. 1. The conductors are supposed to carry short-circuit currents. The aim of the paper is to investigate the volumetric Joule losses in the wires and shielding jackets and formulate an algorithm for calculation of their heating. Since the fault is a short phenomenon, the process of heating will be assumed adiabatic, i.e., heat is not transferred to the neighbourhood of the conductors. This assumption leads to higher temperatures than those actually occurring in the system. As information about heating serves for evaluating heat stress of the insulation system of the feeding line, the method provides safer values.

The short-circuit currents in the conductors $\mathrm{X}, \mathrm{Y}, \mathrm{Z}$ are expressed by the following formulae:

$$
\begin{aligned}
& i_{\mathrm{X}}(t)=A \mathrm{e}^{-\frac{t}{T_{\mathrm{D}}}} \cdot \cos \omega t, \\
& i_{\mathrm{Y}}(t)=\left(A \mathrm{e}^{-\frac{t}{T_{\mathrm{D}}}}+B\right) \cos \left(\omega t+\frac{2 \pi}{3}\right)+C \mathrm{e}^{-\frac{t}{T_{\mathrm{A}}}}, \\
& i_{\mathrm{Z}}(t)=\left(A \mathrm{e}^{-\frac{t}{T_{\mathrm{D}}}}+B\right) \cos \left(\omega t-\frac{2 \pi}{3}\right)-C \mathrm{e}^{-\frac{t}{T_{\mathrm{A}}}},
\end{aligned}
$$

where $A, B, C, T_{\mathrm{A}}$, and $T_{\mathrm{D}}$ are the parameters of the shortcircuit current.

\section{MATHEMATICAL MODEL}

The task can be solved with a sufficient accuracy as a weakly coupled electromagnetic-thermal problem. The electromagnetic phenomena are not tightly connected with the thermal effects and may be solved separately.

\subsection{Electromagnetic field in the feeding conductors}

The field in the conductors is quasistationary. With respect to a relatively low frequency, the skin effect in these conductors may be neglected. This field can be expressed in terms of the magnetic vector potential $\boldsymbol{A}$, whose distribution is described by the equation (see [3], [4])

$\operatorname{curl} \frac{1}{\mu} \operatorname{curl} \boldsymbol{A}=-\gamma \frac{\partial \boldsymbol{A}}{\partial t}+\boldsymbol{J}_{\mathrm{ext}}$,

where $\mu$ and $\gamma$ are permeability and electric conductivity of medium and $\boldsymbol{J}_{\mathrm{ext}}$ is the external current density. For the feeding lines there holds

$$
\begin{aligned}
& \boldsymbol{A}=z_{0} A(x, y, t), \\
& \boldsymbol{J}_{\mathrm{ext}}=z_{0} J_{z, i}(t)=z_{0} \frac{i_{i}(t)}{S_{i}}, \quad i=\mathrm{X}, \mathrm{Y}, \mathrm{Z},
\end{aligned}
$$

where currents $i_{i}(t)$ are given by (1) and $S_{i}$ are the cross sections of conductors $\mathrm{X}, \mathrm{Y}, \mathrm{Z}$. If the conductors are electrically conductive ropes, their cross-sections have to be multiplied by the corresponding coefficient of filling $k_{\mathrm{p}}$. 

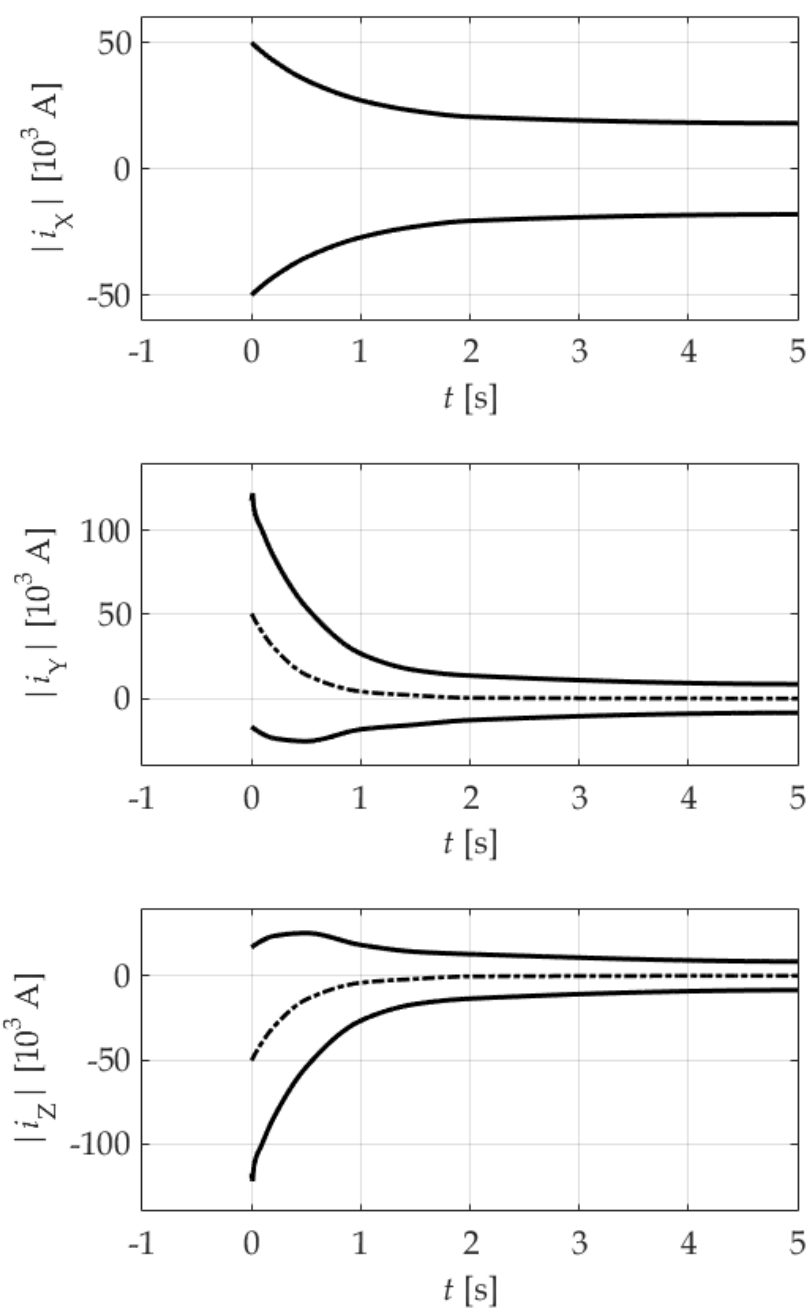

Fig. 2 Time evolution of amplitudes of short-circuit currents $i_{\mathrm{X}}, i_{\mathrm{Y}}, i_{\mathrm{Z}}$

In this way, for particular subdomains the equation (2) has to be modified appropriately:

- conductors $\mathrm{X}, \mathrm{Y}, \mathrm{Z}$ :

$$
\frac{\partial^{2} A_{\mathrm{z}}}{\partial x^{2}}+\frac{\partial^{2} A_{\mathrm{z}}}{\partial y^{2}}=\mu_{0} J_{z, i},
$$

- electric insulation and air:

$$
\frac{\partial^{2} A_{\mathrm{z}}}{\partial x^{2}}+\frac{\partial^{2} A_{\mathrm{z}}}{\partial y^{2}}=0
$$

- shielding shells:

$$
\frac{\partial}{\partial x} \frac{1}{\mu} \frac{\partial A_{\mathrm{z}}}{\partial x}+\frac{\partial}{\partial y} \frac{1}{\mu} \frac{\partial A_{\mathrm{z}}}{\partial y}=\gamma \frac{\partial A_{\mathrm{z}}}{\partial t}
$$

The shielding shells are made of steel whose saturation curve $B=B(H)$ is known.

The volumetric Joule losses per unit length in conductors $\mathrm{X}, \mathrm{Y}, \mathrm{Z}$ carrying short-circuit currents $i_{i}(t)$ are

$w_{\mathrm{c}}(t)=\frac{R_{i} i_{i}^{2}}{S_{i} l}, \quad i=\mathrm{X}, \mathrm{Y}, \mathrm{Z}$, where $R_{i}$ is the resistance of the $i$ th conductor of length $l$, diameter $d_{i}$ and cross section $S_{i}$, with possible respecting the skin effect (4). If the conductor is an electrically conductive rope, the skin effect can be neglected, so that

$R_{i}=\frac{4 l}{\pi \gamma_{\mathrm{Cu}} d_{i}^{2} k_{\mathrm{p}}}, \quad i=\mathrm{X}, \mathrm{Y}, \mathrm{Z}$.

For copper conductors $\gamma_{\mathrm{Cu}}=5.7 \cdot 10^{7} \mathrm{~S} / \mathrm{m}$.

The time evolution of the volumetric Joule losses in the $i$-th shielding jacket is

$w_{\mathrm{s} i}=\frac{J_{z, i}^{2}}{\gamma_{\mathrm{Fe}}}$

where

$J_{z, i}=\gamma_{\mathrm{Fe}} \frac{\partial A_{z, i}}{\partial t}$

For steel shielding shells $\gamma_{\mathrm{Fe}}=5.0 \cdot 10^{6} \mathrm{~S} / \mathrm{m}$ and $\mu=B / H$; this value is for any $B$ found from the saturation curve $B=B(H)$.

The time evolution of the volumetric Joule losses in the $i$ th shielding shell is

$w_{\mathrm{s}, i, \operatorname{avrg}}(t)=\frac{1}{V_{i}} \int_{V_{i}} w_{s, i}(x, y, t) \mathrm{d} V_{i}$,

where $V_{i}$ is the volume of the $i$-th jacket.

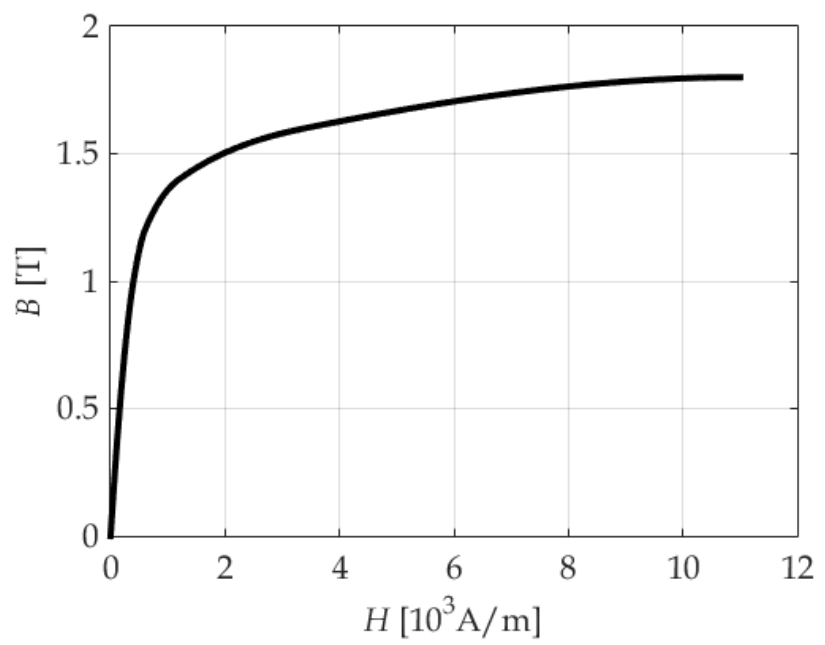

Fig. 3 Magnetization curve of the steel used for shielding

\subsection{Nonstationary temperature field}

Its distribution in the conductors $\mathrm{X}, \mathrm{Y}, \mathrm{Z}$ of length $l$ is given by the balance among the heat fluxes $(\operatorname{grad} T)$, internal energy of the conductors (temperature $T$ ) and energy transported by the heat sources (losses $w_{\mathrm{c}}$ ). The corresponding heat transfer equation reads [4]

$\frac{\partial}{\partial x}\left(\lambda \frac{\partial T}{\partial x}\right)+\frac{\partial}{\partial y}\left(\lambda \frac{\partial T}{\partial y}\right)=\rho c \frac{\partial T}{\partial t}-w_{\mathrm{c}, i}$

where $T=T(x, y, t)$ is the temperature, $\lambda$ denotes the thermal conductivity, $\rho$ stands for the specific mass and $c$ is the specific heat. 
An approximate integral formulation of the relation for temperature rise of conductors $\mathrm{X}, \mathrm{Y}, \mathrm{Z}$ of length $l$ follows from the balance between the internal energy of the conductors and energy transported by the heat sources. The adiabatic heating of wire $\mathrm{X}$ (for example) is described by the relation

$\int_{0}^{t} w_{\mathrm{c}, \mathrm{X}}(t) \mathrm{d} t=\rho c T(t)$

where $w_{\mathrm{c}, \mathrm{X}}$ is given by equation (7).

For numerical computation, equation 13 is discretized as follows

$\sum_{0}^{N} w_{\mathrm{c}, \mathrm{X}, i} \Delta t_{j}=\rho c \sum_{j=0}^{N} \Delta T_{j} \Rightarrow \Delta T_{j}=\frac{1}{\rho c} w_{\mathrm{c}, \mathrm{X}, j} \Delta t_{j}$,

where $\Delta T_{j}$ is the increase of temperature of the conductor in the $j$-th step of length $\Delta t_{j}$. The total temperature rise $\Delta T$ of the conductor for $N$ intervals $\Delta t_{j}$ is

$\Delta T=\sum_{j=0}^{N} \Delta T_{j}$

Similarly we can obtain the temperature rise of the shielding shells produced by the specific Joule losses $w_{\mathrm{s} i}$.

\section{ILLUSTRATIVE EXAMPLE: HEATING OF CON- DUCTOR X AND ITS SHIELDING SHELL}

\subsection{Input data}

- Arrangement and dimensions of the supply are in Fig. 1 .

- Short-circuit currents in the conductors are expressed by (1) and the corresponding parameters are $A=$ $58.8 \cdot 10^{3} \mathrm{~A}, B=8.4 \cdot 10^{3} \mathrm{~A}, C=50.4 \cdot 10^{3} \mathrm{~A}, T_{\mathrm{A}}=$ $0.4 \mathrm{~s}, T_{\mathrm{D}}=0.8 \mathrm{~s}, f=50 \mathrm{~Hz}$ (see Fig. 2).

- Material parameters of conductors X, Y, Z:

Massive copper conductors: $\mu_{r}=1, \gamma_{\mathrm{Cu}}=5.7 \cdot 10^{7}$ $\mathrm{S} / \mathrm{m}, \rho=8966 \mathrm{~kg} / \mathrm{m}^{3}, c=383 \mathrm{~J} /(\mathrm{kg} . \mathrm{K})$

Steel shielding shells: $\gamma_{\mathrm{Fe}}=5.0 \cdot 10^{6} \mathrm{~S} / \mathrm{m}, \rho=7840$ $\mathrm{kg} / \mathrm{m}^{3}, c=465 \mathrm{~J} /(\mathrm{kg} . \mathrm{K})$, the saturation curve is in Fig. 3 .

\subsection{Discussion of the results}

The computation of the temperature rise was first carried out for conductor $\mathrm{X}$ (that is placed between the conductors $\mathrm{Y}$ and $\mathrm{Z}$ - see Fig. 11, whose temperature is expected to reach the maximum value. The calculations were performed using the approximate integral formulation that is, from the numerical viewpoint, less demanding than solution of the presented partial differential equation (12). First, however, a time step had to be determined ensuring the convergence of the numerical process. It was found that for reaching the accuracy on the level of three valid digits this step must satisfy the condition $\Delta t_{j} \leq 0.002 \mathrm{~s}$.

Conductor X: Fig. 4 shows the average value of the volumetric Joule losses $w_{\mathrm{cX}}$ caused by the short-circuit current
$i_{\mathrm{X}}(t)$. Fig. 5 depicts the time evolution of contributions of the temperature $\Delta T_{j}$ and resultant temperature rise $\Delta T$.

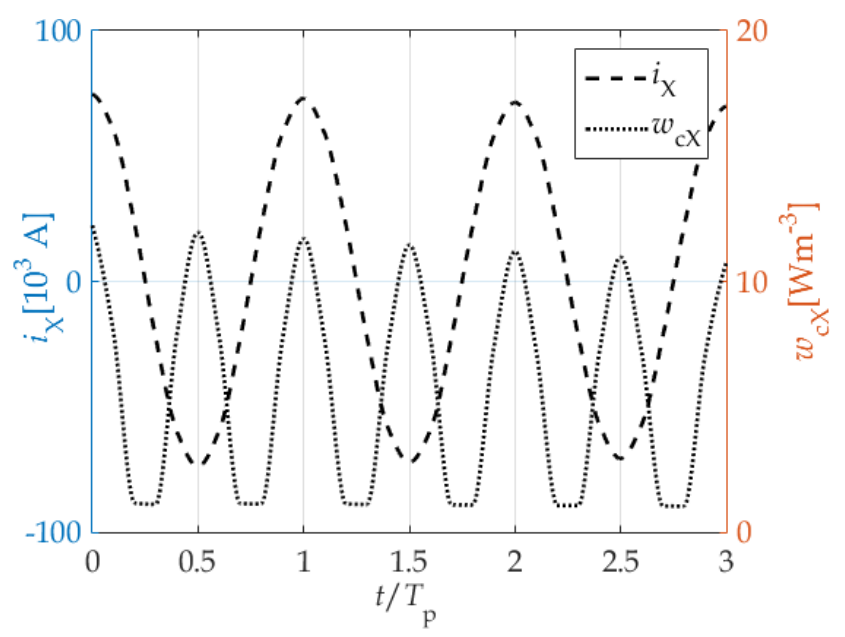

Fig. 4 Average value of the volumetric Joule losses $w_{\mathrm{cX}}(t)$ caused by the short-circuit current $i_{\mathrm{X}}(t)$

Shielding shell of conductor X: Fig. 6 shows the average values of eddy current densities $J_{z}$ and corresponding average value of the Joule losses $W_{\mathrm{sX}}$. Finally, Fig. 7 depicts the time evolution of contributions of temperature $\Delta T_{j}$ and resultant temperature rise $T(t)$.

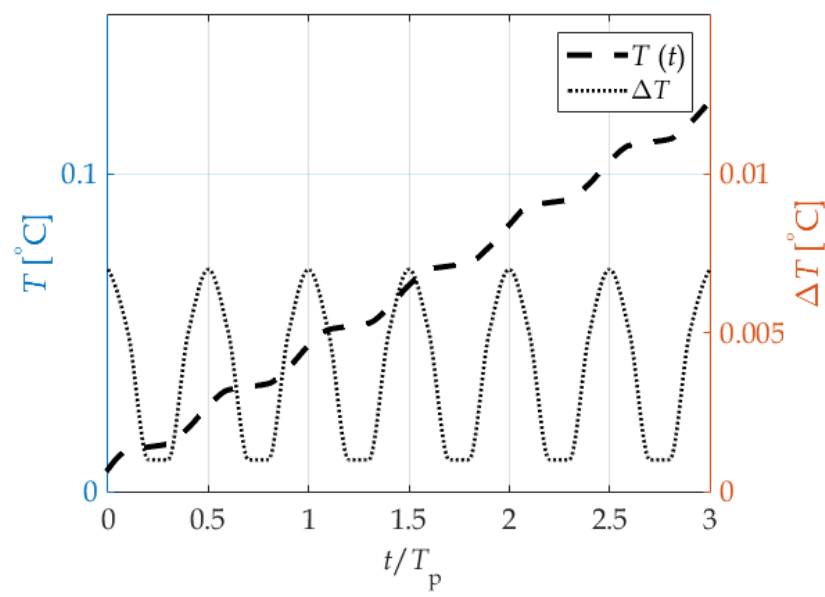

Fig. 5 Time evolution of increments of temperature $\Delta T(t)$ and average temperature $T(t)$ of conductor $\mathrm{X}$

Figures 5 and 7 show that the total temperature rise of the conductor $\mathrm{X}$ is higher than the temperature rise of its shielding shell. In the course of three periods of the shortcircuit current $\left(t / T_{\mathrm{p}}=3\right)$, the conductor $\mathrm{X}$ exhibits total temperature rise $\Delta T=0.123^{\circ} \mathrm{C}$, while the total temperature rise of the shielding shell is only $\Delta T=0.0021^{\circ} \mathrm{C}$. This is obviously caused by the influence of the shielding shell (or more accurately, by the gap between the conductor and shell) and lower electric conductivity of the shell with respect to the copper conductor. Consequently, eddy currents heating the steel shell are significantly lower than the shortcircuit currents heating the conductor. Another role is also played by greater volume of the shell with respect to the volume of the conductor. 


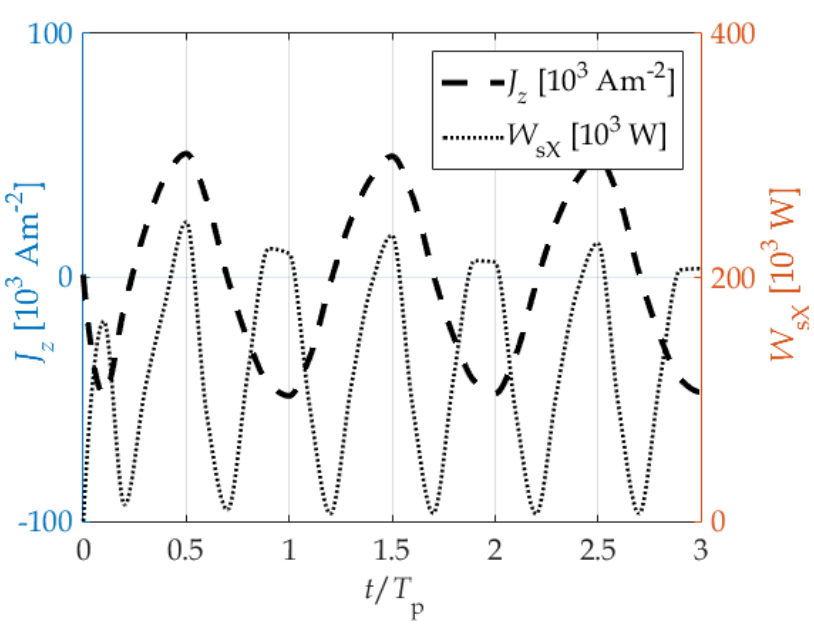

Fig. 6 Average values of eddy current densities $J_{z}$ and corresponding average value of Joule losses $W_{\mathrm{sX}}(t)$ in shielding of conductor X

The aim of this work is to introduce a calculation method of the heating process of the shielded three-phase supply with short-circuit currents. Therefore, we evaluate only the first three periods of short-circuit currents. It is necessary to remark, that the calculation of the heating was performed under the assumption of adiabatic heating, where the heat generated in the conductors and shielding jackets is not dissipated by convection and radiation and it is used to raise the temperature of these parts. This assumption is justified, since the transient phenomenon of short circuit is very short. Then the calculation is simplified and gives somewhat higher values of temperature than its real value. Therefore, for design of such feeding line, such results are safer.

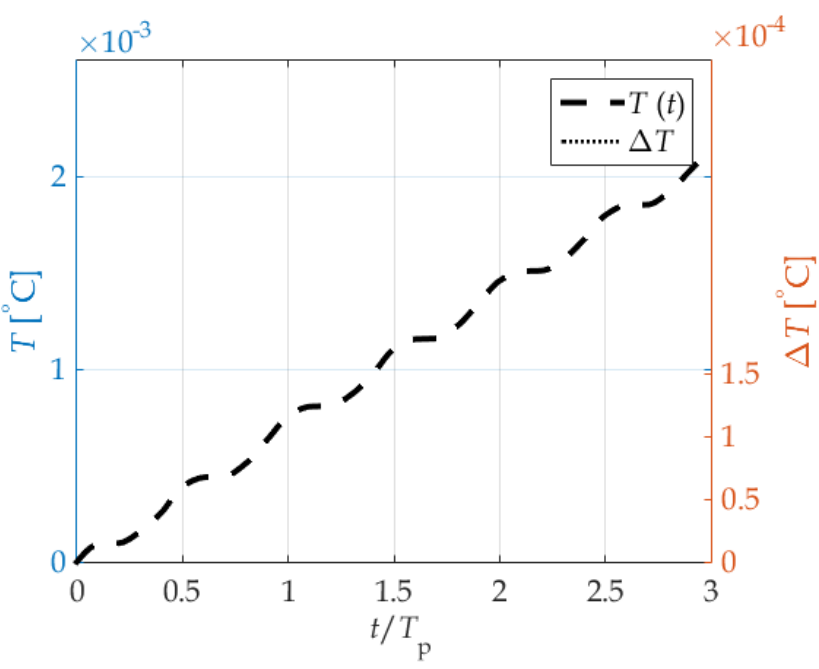

Fig. 7 Time evolution of increments $\Delta T(t)$ and average temperature $T(t)$ of shielding shell of conductor $\mathrm{X}$

\section{ACKNOWLEDGEMENT}

This work was supported by the project SGS-2015-035 at the University of West Bohemia.

\section{REFERENCES}

[1] MAYER, D. - ULRYCH, B. - POLCAR, P.: Forces acting on the shielded three-phase supply, Acta Electrotechnica et Informatica 14, No. 4 (2014) 31-34

[2] MAYER, D. - ULRYCH, B. - KROPÍK, P.: Effect of electromagnetic shielding on forces acting among conductors of three-phase lines, Computational Problems of Electrical Engineering 4, No. 1 (2014) 33-38

[3] MAYER, D. - ULRYCH, B.: Numerical approach for computation of electromagnetic shielding, Journ. El. Eng. 64, No. 4 (2013) 256-260

[4] MAYER, D.: Applied electromagnetism, Publishing House Kopp, Ceske Budejovice, 2012.

[5] ŠORIN, S. N.: Heat exchange, Publishing House SNTL/ALFA, Praha, 1968.

[6] www.quickfield.com

Received January 18, 2016, accepted March 4, 2016

\section{BIOGRAPHIES}

Daniel Mayer - Prof., Ing., DrSc. (1930) Received the Ing., PhD. and DrSc degrees in electrical engineering from Technical University in Prague, Czech Republic. In 1959 Associate Professor at the University of West Bohemia in Pilsen, in 1968 Full Professor of the Theory of Electrical Engineering. Many years he was head of the Department of Theory of Electrical Engineering. Research interests: circuit theory, electromagnetic field theory, electrical machines and apparatus, history of electrical engineering. He published 7 books, more than 330 scientific papers and 10 patents. He is a member of many editorial boards of several international journals and leader of many grant projects.

Bohuš Ulrych - Assoc. Prof. (1937) works in the Department of Theory of Electrical Engineering at the Faculty of Electrical Engineering of the University of West Bohemia in Pilsen, Czech Republic in Pilsen. His professional interests are aimed at modern numerical methods for solution of physical fields and engineering applications. $\mathrm{He}$ is an author or co-author of about 250 papers, several books and textbooks, and a lot of software for teaching and calculation of electromagnetic fields and coupled problems (ulrych@kte.zcu.cz).

Petr Kropík - Ing., Ph.D. (1971) graduated from the Faculty of Applied Science UWB in the branch of computer science. He was employed at SPT Telecom a. s. and after three years he became an Assistant at the Department of Theory of Electrical Engineering. In 2009 he finished his doctoral studies in Department of Theory of Electrical Engineering (supervisor Prof. Mayer). He teaches subjects in the domain of computer science. His professional interests include optimization methods, software engineering (Java, C++, MATLAB, LabView), embedded systems and networks. He is an author and coauthor of more than 40 papers mostly in the domain of optimization problems of physical fields. 